\title{
Conversion to IPX066 from Standard Levodopa Formulations in Advanced Parkinson's Disease: Experience in Clinical Trials
}

\author{
Paul A. Nausieda ${ }^{\mathrm{a}, *}$, Ann Hsu ${ }^{\mathrm{b}}$, Lawrence Elmer ${ }^{\mathrm{c}}$, Ramon A. Gil ${ }^{\mathrm{d}}$, Joerg Spiegel ${ }^{\mathrm{e}}$, Carlos Singer ${ }^{\mathrm{f}}$, \\ Sarita Khanna ${ }^{\mathrm{b}}$, Robert Rubens ${ }^{\mathrm{b}}$, Sherron Kell ${ }^{\mathrm{b}}$, Nishit B. Modi ${ }^{\mathrm{b}}$ and Suneel Gupta ${ }^{\mathrm{b}}$ \\ ${ }^{a}$ Wisconsin Institute for Neurologic and Sleep Disorders, Milwaukee, WI, USA \\ ${ }^{\mathrm{b}}$ Impax Laboratories, Inc., Hayward, CA, USA \\ ${ }^{\mathrm{c}}$ University of Toledo College of Medicine, Toledo, OH, USA \\ ${ }^{\mathrm{d}}$ Charlotte Neurological Services, Port Charlotte, FL, USA \\ ${ }^{\mathrm{e}}$ Saarland University, Homburg/Saar, Germany \\ ${ }^{\mathrm{f}}$ University of Miami, Miami, FL, USA
}

\begin{abstract}
.
Background: Due to the short half-life of levodopa, immediate-release carbidopa-levodopa (IR CD-LD) produces fluctuating LD concentrations, contributing to a risk of eventual motor complications. IPX066 was designed to rapidly attain therapeutic LD concentrations and maintain them to allow a dosing interval of $\sim 6$ hours.

Objective: To extensively analyze the dosing data collected in IPX066 studies during open-label conversions from IR CD-LD alone or with entacapone (CLE) and identify patterns relevant for managing conversion in the clinical setting.

Methods: Patients had $\geq 2.5$ hours/day of "off" time despite a stable IR or CLE regimen. Suggested initial dosing conversion tables based on prior LD daily dosage were provided.

Results: Of 450 patients previously treated with IR CD-LD and 110 with CLE, $87.3 \%$ and $82.7 \%$ completed conversion to IPX066, respectively. At the end of conversion, average IPX066 LD daily dosages were higher than pre-conversion dosages, with a mean conversion ratio of $2.1 \pm 0.6$ for IR CD-LD and $2.8 \pm 0.8$ for CLE; $>90 \%$ of patients took IPX066 3 or 4 times/day, compared with a median of 5 times/day at baseline in both studies. After conversion, daily "off" time significantly decreased, with no significant increase in troublesome dyskinesia. The most common adverse event reported during conversion was nausea, with an incidence of 5.3\% for conversion from IR and 7.3\% from CLE.

Conclusions: Among PD patients with substantial "off" time, a majority were safely converted to IPX066. The sustained LD profile from the IPX066 formulation allowed an increase in LD dose accompanied by improved motor functions, without increased troublesome dyskinesia.
\end{abstract}

Keywords: Levodopa, Parkinson's disease, dyskinesia, off-time, on-time, extended-release

\footnotetext{
${ }^{*}$ Correspondence to: Paul A. Nausieda, MD, Wisconsin Institute for Neurologic and Sleep Disorders, $945 \mathrm{~N}$. 12th St, Suite 4602, Milwaukee, WI 53233, USA. Tel.: +1 414219 7450; Fax: +1 414219 5799; E-mail: nausiedamd@parkcent.com.
}

\section{INTRODUCTION}

Levodopa (LD) administered orally with the peripheral dopa-decarboxylase inhibitor carbidopa (CD) is a highly effective treatment of the motor symptoms of 
Parkinson's disease (PD) and is extensively used in all stages of the disease $[1,2]$. However, the short half-life of LD, approximately 1.5 hours $[3,4]$, results in large peak-to-trough fluctuations in plasma concentrations even when LD is dosed frequently, with a consequent increase in risk of eventual motor complications $[5,6]$. To prolong the half-life, the immediate-release (IR) formulation of CD-LD may be combined with a catechol-O-methyltransferase (COMT) inhibitor such as entacapone [7]. Alternatively, CD-LD may be administered as a controlled-release (CR) formulation. However, CR CD-LD has shown slow, sometimes unpredictable absorption [8-11], perhaps contributing to patient reports of delayed onset and decreased predictability of response [8, 9, 12, 13].

IPX066 (marketed as Rytary ${ }^{\circledR}$ [carbidopa and levodopa] extended release capsules) is an oral extended-release CD-LD formulation designed to rapidly achieve therapeutic LD plasma concentrations and maintain them for a prolonged duration [14], allowing dosing at 6-hour intervals in both early and advanced PD patients. Randomized, double-blind, active-comparator-controlled clinical trials have tested the efficacy and safety of IPX066 in advanced PD previously treated with IR CD-LD (ADVANCE-PD) [15] or with IR CD-LD plus entacapone (CLE, dosed separately or as combination tablets; ASCEND-PD) [16]. In both studies, the benefits of conversion to IPX066 included statistically significant decreases in daily "off" time and increases in daily "on" time without troublesome dyskinesia. In addition, a long-term open-label study [17] has demonstrated successful conversion to IPX066 from CR CD-LD taken alone or in combination with IR CD-LD for advanced PD. In this study, the identified benefits included patient preference for IPX066 and patient- and clinician-rated global improvement. In all 3 studies, IPX066 safety findings were consistent with those for standard CDLD formulations.

In advanced PD patients receiving a single dose of IPX066, the LD exposure (as measured by AUC, the area under the time curve of LD plasma level) averaged approximately $70 \%$ and the peak plasma $\mathrm{LD}$ concentration $\left(\mathrm{C}_{\max }\right)$ averaged approximately $30 \%$ of the values following a single dose of IR CD-LD [14]. Because the LD plasma profiles provided by IPX066 are substantially different from those of other LD products [18], changes in LD dose and dosing frequency are expected in patients switching to IPX066 from other LD products. Indeed, a recent review of IPX066 administration [19] emphasizes that its doses are not simply interchangeable with those of standard forms of CD-LD. The review urges clinicians to be familiar with proper dosing, have a plan in place for patients to provide feedback concerning treatment response, and be prepared to make regimen adjustments. Here we evaluate more extensively than in previous reports $[15,16,20,21]$ the dosing data collected during the conversion periods of the clinical studies of IPX066 versus IR CD-LD (ADVANCE-PD [15]) and versus CLE (ASCEND-PD [16]), with the aim of discerning patterns relevant for managing such conversions in the clinical setting.

\section{METHODS}

\section{Study designs}

ADVANCE-PD was a randomized, double-blind, double-dummy, parallel-group study of IPX066 versus IR CD-LD. Over a 3-week period, each patient's pre-study IR CD-LD regimen was adjusted, based on clinical need. During the subsequent 6 weeks, patients were converted to IPX066 in an open-label fashion. Patients then received either the IPX066 regimen or the IR regimen for 13 weeks in a double-blind phase. ASCEND-PD was a randomized, double-blind, double-dummy, crossover study of IPX066 versus CLE. Patients, who were required to be on a stable CLE regimen for at least 4 weeks at study entry, were converted from CLE to IPX066 over a 6-week period in an open-label fashion. This was followed by two 2-week, double-blind treatment periods in random order, one of them on IPX066, the other on each patient's pre-study CLE regimen. The double-blind treatment periods were separated by a week of openlabel IPX066 treatment. During both studies, patients were required to continue any use of amantadine, anticholinergics, selective monoamine oxidase type B inhibitors (e.g., selegiline, rasagiline), or dopamine agonists at dosages that had been stable for at least 4 weeks preceding screening, but were not permitted to initiate such agents or use any non-study LD preparations.

\section{Study participants}

In both studies, all patients were required to have a diagnosis of idiopathic PD by UK Parkinson's Disease Brain Bank Criteria [22], identified at an age $\geq 30$ years and at Hoehn \& Yahr [23] stage 1 to 4 during an "on" state. All patients were also required to have been on a stable regimen of oral CD-LD for at least 4 weeks prior 
to screening, taken at least 4 times/day and totaling at least $400 \mathrm{mg} /$ day of LD. In ADVANCE-PD, the prior LD therapy was from IR CD-LD; in ASCEND-PD, it was from IR CD-LD plus entacapone. Despite these treatments, all patients had at least 2.5 hours per day of "off" time during waking hours.

\section{Conversion to IPX066}

In both studies, each patient's conversion to IPX066 was conducted during a 6-week open-label period. To help identify an appropriate initial IPX066 regimen, study investigators were given a conversion table based on the pre-study LD daily dosage (Table 1). The suggested initial IPX066 LD daily dosages were higher than in the pre-study LD regimens, based on pharmacokinetic studies demonstrating that IPX066 produces an LD AUC and $\mathrm{C}_{\max }$ lower than those of an equal dose of IR CD-LD [14]. In addition, a study in advanced PD patients had demonstrated that the anticipated higher daily doses of IPX066 resulted in a reduction in "off" time without a significant increase in troublesome dyskinesia [14]. Entacapone increases the LD AUC, compared with IR CD-LD alone; hence, the suggested initial IPX066 doses were approximately 30\% higher for conversion from CLE (Table 1, bottom) than for conversion from IR CD-LD (Table 1, top). Because IPX066 prolongs the duration of elevated LD concentrations [18], the suggested initial dosing frequency for all conversions was at 6-hour intervals during the waking day, regardless of a patient's pre-study LD dosing frequency, resulting in either a t.i.d. regimen (without bedtime dosing) or a q.i.d. regimen (with bedtime dosing). During the conversion period, the regimen could be adjusted at the investigator's discretion, but dosing more than 5 times daily or at less than 4-hour intervals was discouraged. The overall goal was to minimize "off" time without causing troublesome dyskinesia.

\section{Outcome measures for dose conversion}

In each study, LD daily dosages and dosing frequencies were collected at baseline, and IPX066 dosages and dosing frequencies were collected at the end of the 6-week conversion period. IPX066 dose adjustments during conversion were recorded and the LD conversion ratios were estimated.

\section{Conversion-data analyses}

Baseline demographics and PD characteristics of all patients exposed to IPX066 were assessed descriptively for differences between patients who completed conversion and dropouts. For patients who completed conversion, mean conversion ratios were calculated for conversion from IR CD-LD and from CLE to IPX066. The proportion of patients who required adjustments

Table 1

Suggested initial regimens for conversion to IPX066 in clinical trials

\begin{tabular}{|c|c|c|}
\hline $\begin{array}{l}\text { LD dosage at study entry, } \\
\text { as IR CD-LD } \\
\text { (mg/day) }\end{array}$ & $\begin{array}{l}\text { Suggested initial } \\
\text { LD dosage from } \\
\text { IPX066 (mg/day) }\end{array}$ & $\begin{array}{l}\text { Suggested initial } \\
\text { IPX066 regimen }\end{array}$ \\
\hline \multicolumn{3}{|c|}{ ADVANCE-PD } \\
\hline $400-550$ & 855 & 3 capsules $\times 95 \mathrm{mg}$ t.i.d. ${ }^{\mathrm{a}}$ \\
\hline $551-750$ & 1,140 & 4 capsules $\times 95 \mathrm{mg}$ t.i.d. ${ }^{\mathrm{a}}$ \\
\hline $751-950$ & 1,305 & 3 capsules $\times 145 \mathrm{mg}$ t.i.d. ${ }^{\mathrm{a}}$ \\
\hline $951-1,250$ & 1,755 & 3 capsules $\times 195 \mathrm{mg}$ t.i.d. ${ }^{\mathrm{a}}$ \\
\hline $1,251-1,650$ & 2,205 or 2,340 & 3 capsules $\times 245 \mathrm{mg}$ t.i.d. ${ }^{\mathrm{a}}$ \\
\hline$>1,650$ & 2,940 & $\begin{array}{c}\text { or } \\
4 \text { capsules } \times 195 \mathrm{mg} \text { t.i.d. }{ }^{\mathrm{a}}{ }^{\mathrm{a}} \text { capsules } \times 245 \mathrm{mg} \text { t.i.d. }\end{array}$ \\
\hline LD dosage at study entry, & Suggested initial & Suggested initial \\
\hline as IR CD-LD with adjunctive & LD dosage from & IPX066 regimen \\
\hline entacapone (mg/day) & IPX066 (mg/day) & \\
\hline \multicolumn{3}{|c|}{ ASCEND-PD } \\
\hline $400-550$ & 1,140 & 4 capsules $\times 95 \mathrm{mg}$ t.i.d. ${ }^{\mathrm{a}}$ \\
\hline $551-750$ & 1,470 & 2 capsules $\times 245 \mathrm{mg}$ t.i.d. ${ }^{\mathrm{a}}$ \\
\hline $751-950$ & 1,755 & 3 capsules $\times 195 \mathrm{mg}$ t.i.d. ${ }^{\mathrm{a}}$ \\
\hline $951-1,250$ & 2,205 & 3 capsules $\times 245 \mathrm{mg}$ t.i.d. ${ }^{\mathrm{a}}$ \\
\hline$>1,250$ & 2,940 & 4 capsules $\times 245 \mathrm{mg}$ t.i.d. ${ }^{\mathrm{a}}$ \\
\hline
\end{tabular}


from their suggested initial IPX066 daily dosage, the extent of dosage adjustment, and the proportion of patients on various IPX066 dosing frequencies at the end of conversion were also assessed.

\section{Efficacy measures}

During the 3 days preceding the start and the 3 days preceding the end of the conversion period, patients in both studies maintained a home PD diary [24]. For each half-hour, patients recorded whether they had been asleep, "off," "on" without dyskinesia, "on" with non-troublesome dyskinesia, or "on" with troublesome dyskinesia. For conversion completers, mean changes from baseline to the end of conversion in the 3-day averages for daily "off" time, "on" time without troublesome dyskinesia ("on" time without dyskinesia plus "on" time with non-troublesome dyskinesia), and "on" time with troublesome dyskinesia are presented.

\section{Safety/tolerability measures}

During the 6-week conversion period in each study, adverse events (AEs) and AEs leading to patient discontinuations were recorded, and were categorized using Medical Dictionary for Regulatory Activities (MedDRA) Version 12.1 Preferred Terms.

\section{Ethical conduct}

Both studies were conducted in accordance with Good Clinical Practice guidelines promulgated by the International Conference on Harmonisation, and were approved by appropriate institutional review boards. Prior to study procedures, all patients provided written informed consent.

\section{RESULTS}

\section{Patient disposition}

Of the 560 PD patients who underwent conversion to IPX066, 87.3\% of those who had been taking IR CDLD (393 of 450) and $82.7 \%$ of those who had been taking CLE (91 of 110) completed conversion (Fig. 1). Patient characteristics for conversion completers and for dropouts during conversion are provided in Table 2.

\section{Concomitant medications}

The use of other anti-parkinsonian medications and antidepressants at study entry is summarized in Table 2. Overall, the proportions of patients taking each class of medication were similar in conversion completers and dropouts.

\section{Dosage adjustments}

For conversion completers, LD dosages and dosing frequencies prior to the start of conversion and at the end of conversion to IPX066 are presented in Table 3. At the end of conversion from IR CD-LD, $24.9 \%$ of completers were on the dose recommended by the study's conversion table, $59.5 \%$ were on a higher dose, and $15.5 \%$ were on a lower dose. The median percent change in IPX066 dosage from the initial recommended dosage was $+14.5 \%$ (mean, $+21.0 \%$ ). Of the 393 completers, $165(42.0 \%)$ increased their dosage by $\leq 50 \%$ from the initial recommended dosage, and $32(8.1 \%)$ increased it by $>75 \%$.

At the end of conversion from CLE, $30.8 \%$ of completers were on their initial recommended IPX066 dosage, $56.0 \%$ were on a higher dose, and $13.2 \%$ were

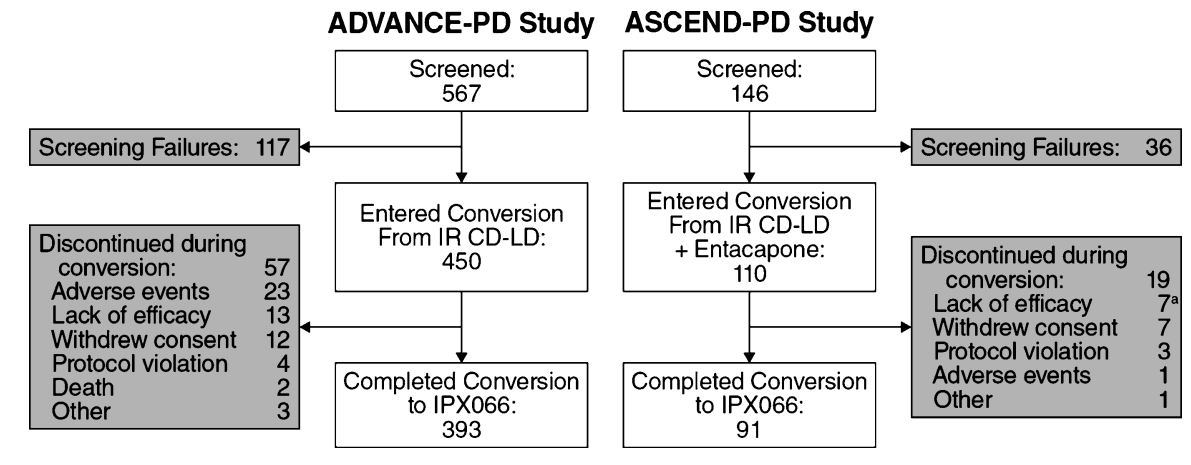

Fig. 1. Patient disposition. ancludes 2 patients who received placebo due to study-site error. CD, carbidopa; IR, immediate-release; LD, levodopa. 
Table 2

Patients' baseline characteristics

\begin{tabular}{|c|c|c|c|c|}
\hline \multirow[t]{2}{*}{ Variable } & \multicolumn{2}{|c|}{ Conversion from IR CD-LD $(N=450)$} & \multicolumn{2}{|c|}{ Conversion from CLE $(N=110)$} \\
\hline & $\begin{array}{l}\text { Conversion } \\
\text { completers }\end{array}$ & $\begin{array}{l}\text { Dropouts during } \\
\text { conversion }\end{array}$ & $\begin{array}{l}\text { Conversion } \\
\text { completers }\end{array}$ & $\begin{array}{c}\text { Dropouts during } \\
\text { conversion }\end{array}$ \\
\hline$n$ & 393 & 57 & 91 & $19^{\mathrm{a}}$ \\
\hline Age (years), mean (SD) & $63.2(9.4)$ & $63.6(9.9)$ & $64.1(9.3)$ & $66.7(7.7)$ \\
\hline Males, $n(\%)$ & $254(64.6)$ & $29(50.9)$ & $68(74.7)$ & $8(42.1)$ \\
\hline Whites, $n(\%)$ & $382(97.2)$ & $53(93.0)$ & $89(97.8)$ & $19(100.0)$ \\
\hline Age at PD diagnosis (years), mean (SD) & $55.8(10.2)$ & $54.5(10.5)$ & $54.1(9.6)$ & $56.0(8.7)$ \\
\hline PD duration (years), mean (SD) & $7.4(4.5)$ & $9.1(6.2)$ & $10.0(5.3)$ & $10.7(4.9)$ \\
\hline LD treatment duration (years), mean (SD) & $5.8(4.2)$ & $7.7(6.1)$ & $6.8(5.0)$ & $7.9(4.6)$ \\
\hline "Off" time (hours/day), mean (SD) & $6.0(2.1)$ & $6.1(2.0)$ & $5.9(2.6)$ & $5.6(2.4)$ \\
\hline UPDRS II+III score ${ }^{\mathrm{b}}$, mean (SD) & $32.4(14.8)$ & $29.7(15.6)$ & $34.4(16.0)$ & $32.2(11.6)$ \\
\hline LD dosage (mg/day), mean (SD) & $775.8(353.3)$ & $874.6(356.9)$ & $660.4(246.8)$ & $681.6(228.7)$ \\
\hline LD dosing frequency (times/day) Mean (SD) & $5.0(1.6)$ & $5.7(2.2)$ & $5.0(1.2)$ & $4.9(1.1)$ \\
\hline$\geq 5, n(\%)$ & $195(49.6)$ & $36(63.2)$ & $46(54.8)$ & $11(57.9)$ \\
\hline Entacapone dosage (mg/day), mean (SD) & 0 & 0 & $940.7(170.0)$ & $947.4(238.9)$ \\
\hline Entacapone dosing frequency (times/day), mean (SD) & 0 & 0 & $4.7(0.8)$ & $4.7(1.2)$ \\
\hline \multicolumn{5}{|l|}{ Concomitant medications ${ }^{\mathrm{c}}, n(\%)$} \\
\hline Any & $393(100.0)$ & $57(100.0)$ & $91(100.0)$ & $19(100.0)$ \\
\hline DAs & $210(53.4)$ & $35(61.4)$ & $58(63.7)$ & $12(63.2)$ \\
\hline MAOIs & $96(24.4)$ & $21(36.8)$ & 35 (38.5) & $7(36.8)$ \\
\hline Anticholinergics & $26(6.6)$ & $1(1.8)$ & $1(1.1)$ & 0 \\
\hline Antidepressants & $99(25.3)$ & 18 (31.6) & $21(23.1)$ & $4(21.1)$ \\
\hline Amantadine & $83(21.1)$ & $9(15.8)$ & $20(22.0)$ & $3(15.8)$ \\
\hline
\end{tabular}

${ }^{a}$ Includes 2 patients who received placebo due to study-site error. ${ }^{b}$ During the patient's "on" state. ${ }^{c}$ At study entry. CD, carbidopa; CLE, immediate-release carbidopa-levodopa plus entacapone; DAs, dopamine agonists; IR, immediate-release; LD, levodopa; MAOIs, monoamine oxidase inhibitors; PD, Parkinson's disease; SD, standard deviation; UPDRS, Unified Parkinson's Disease Rating Scale.

Table 3

Levodopa dosage and dosing frequency prior to start of conversion and at the end of conversion (conversion completers)

\begin{tabular}{|c|c|c|c|c|}
\hline \multirow[t]{2}{*}{ Variable } & \multicolumn{2}{|c|}{$\begin{array}{l}\text { Conversion from } \\
\text { IR CD-LD }\end{array}$} & \multicolumn{2}{|c|}{$\begin{array}{l}\text { Conversion from } \\
\text { CLE }\end{array}$} \\
\hline & $\begin{array}{l}\text { Prior to start } \\
\text { of conversion } \\
\text { (IR CD-LD) }\end{array}$ & $\begin{array}{l}\text { End of } \\
\text { conversion } \\
\text { to IPX066 }\end{array}$ & $\begin{array}{l}\text { Prior to start } \\
\text { of conversion } \\
\text { (CLE) }\end{array}$ & $\begin{array}{l}\text { End of } \\
\text { conversion } \\
\text { to IPX066 }\end{array}$ \\
\hline$n$ & 393 & 393 & 91 & 91 \\
\hline \multicolumn{5}{|c|}{ LD dosage $^{\text {a }}$ (mg/day) } \\
\hline Mean (SD) & $814.5(356.5)$ & $1,621.7(744.3)$ & $660.4(246.8)$ & $1,791.6(770.8)$ \\
\hline Median & 750 & 1,365 & 600 & 1,560 \\
\hline Range & $400-2,550$ & $570-5,390$ & $400-1,600$ & $735-4,900$ \\
\hline \multicolumn{5}{|c|}{ LD dosage ${ }^{a}$ levels (mg/day), $n(\%)$} \\
\hline 400 to $<800$ & $198(50.4)$ & $14(3.6)$ & $65(71.4)$ & $1(1.1)$ \\
\hline 800 to $<1,200$ & $127(32.3)$ & $127(32.3)$ & $22(24.2)$ & $20(22.0)$ \\
\hline 1,200 to $<1,700$ & $61(15.5)$ & $95(24.2)$ & $4(4.4)$ & $28(30.8)$ \\
\hline 1,700 to $<2,400$ & $5(1.3)$ & $110(28.0)$ & 0 & $30(33.0)$ \\
\hline$\geq 2,400$ & $2(0.5)$ & $47(12.0)$ & 0 & $12(13.2)$ \\
\hline \multicolumn{5}{|c|}{ LD dosing frequency (doses/day) } \\
\hline Mean (SD) & $5.1(1.5)$ & $3.6(0.7)$ & $5.0(1.2)$ & $3.5(0.6)$ \\
\hline Median & 5 & 3 & 5 & 3 \\
\hline Range & $3-18$ & $3-7$ & 4-9 & $3-5$ \\
\hline \multicolumn{5}{|c|}{ LD dosing-frequency levels (doses/day), $n(\%)$} \\
\hline 3 & $1(0.3)$ & $205(52.2)$ & 0 & $52(57.1)$ \\
\hline 4 & $172(43.8)$ & $156(39.7)$ & $40(44.0)$ & $34(37.4)$ \\
\hline 5 & $105(26.7)$ & $31(7.9)$ & 29 (31.9) & $5(5.5)$ \\
\hline 6 & $64(16.3)$ & 0 & $15(16.5)$ & 0 \\
\hline $7-8$ & $39(9.9)$ & $1(0.3)$ & $7(7.7)$ & 0 \\
\hline $9-12$ & $10(2.5)$ & 0 & 0 & 0 \\
\hline$>12$ & $2(0.5)$ & 0 & 0 & 0 \\
\hline
\end{tabular}

${ }^{a}$ In IR CD-LD prior to start of conversion; in IPX066 at end of conversion. CD, carbidopa; CLE, immediate-release carbidopa-levodopa plus entacapone; IR, immediate-release; LD, levodopa; SD, standard deviation. 
on a lower dose. The median percent change in IPX066 dosage from the initial recommended dosage was $+8.3 \%$ (mean, $+19.7 \%$ ). Of the 91 completers, $38(41.8 \%)$ increased their dosage by $\leq 50 \%$ from the initial recommended dosage, and $7(7.7 \%)$ increased it by $>75 \%$.

\section{Dosing frequencies}

At the end of conversion, the mean (SD) IPX066 dosing frequency was 3.6 (0.7) times/day among patients converted from IR CD-LD and $3.5(0.6)$ times/day among patients converted from CLE (see Table 3). The median in both studies was 3 times/day. Among patients converted from IR CD-LD, 52.2\% were taking IPX066 3 times/day and 39.7\% were taking it 4 times/day. Among patients converted from CLE, the proportions were $57.1 \%$ and $37.4 \%$, respectively. Prior to the start of conversion, the mean LD dosing frequency had been 5.1 (1.5) times/day for IR CD-LD and 5.0 (1.2) times/day for CLE. The median for both had been 5 times/day.

\section{Conversion ratios}

Figure 2 charts the LD daily doses of IPX066 versus IR CD-LD (Panel A) or versus CLE (Panel B) for all conversion completers. For conversion from IR CD$\mathrm{LD}$, the mean $(\mathrm{SD})$ conversion ratio, denoted by the slope of a line in the chart, was $2.1(0.6)$, and the median was 1.9. For conversion from CLE, the mean ratio was $2.8(0.8)$ and the median was 2.9. The ratios were generally similar throughout the range of LD daily dose and therefore were largely independent of pre-conversion LD dosage.

\section{Efficacy}

From pre-conversion to end of conversion from IR CD-LD or from CLE, mean changes in diary data among conversion completers showed a statistically significant reduction of daily "off" time, a statistically significant increase in daily "on" time without troublesome dyskinesia, and no significant change in daily "on" time with troublesome dyskinesia (Table 4). In both studies, the improvements were also significant at the end of double-blind IPX066 treatment $[15,16]$.

\section{Safety}

The overall incidence of reported AEs was $45.8 \%$ during conversion from IR CD-LD and $30.9 \%$ dur-
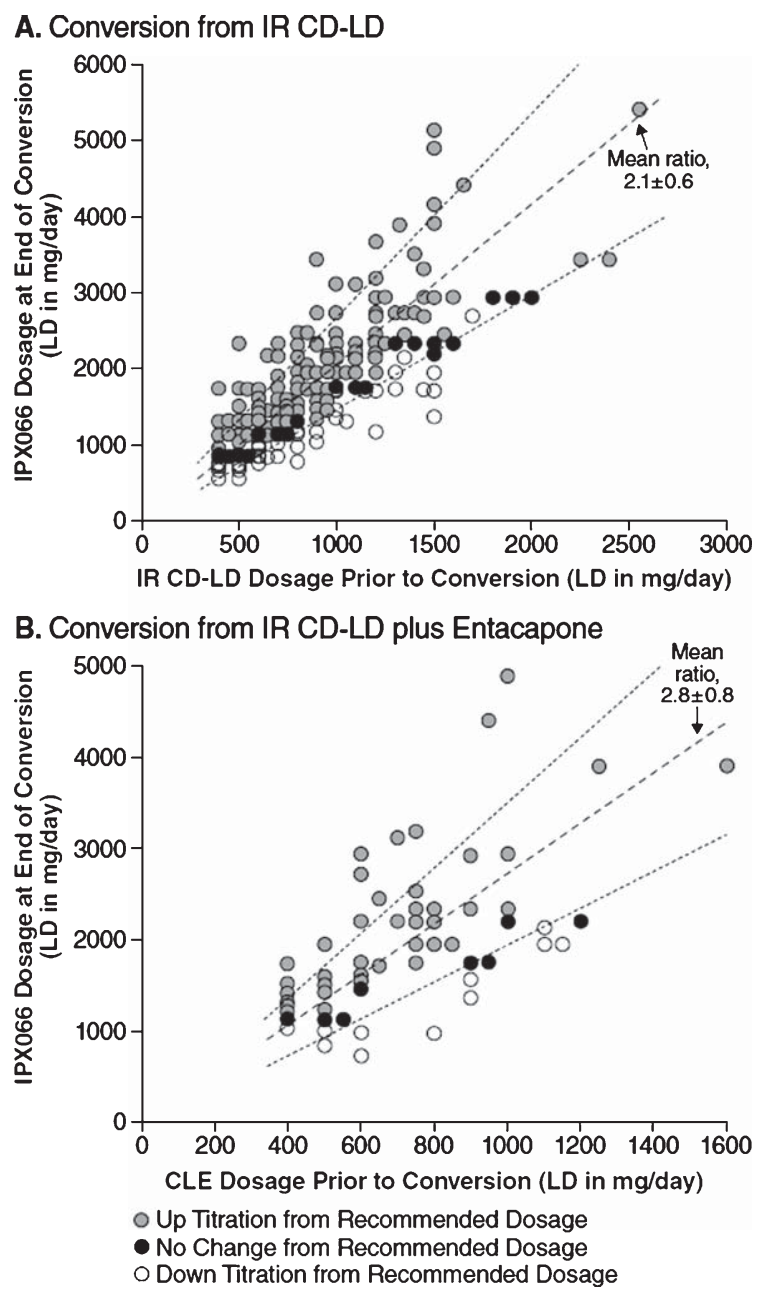

Fig. 2. Distribution of LD daily dosage, end of conversion versus pre-conversion among conversion completers, for conversion to IPX066 from IR CD-LD (A) or from CLE (B), with mean conversion ratios (dashed lines) and their standard deviations (dotted lines). CD, carbidopa; CLE, immediate-release carbidopa-levodopa plus entacapone; IR, immediate-release; LD, levodopa.

ing conversion from CLE (Table 5). The only AE with an incidence $\geq 5.0 \%$ in both studies was nausea, at $5.3 \%$ during conversion from IR CD-LD and 7.3\% during conversion from CLE. The highest severity of most AEs during the conversion periods was mild or moderate. During the double-blind treatment period of each study, no AE had an incidence $\geq 5 \%$ $[15,16]$.

During conversion from IR CD-LD, 23 patients (5.1\%) discontinued due to AEs. The AEs leading to discontinuation of more than one patient were dyskinesia (in 5 patients, or 1.1\%); anxiety, dizziness, and on and off phenomenon (each in 3 patients, or $0.7 \%$ ); and nausea and visual hallucinations (each in 2 patients, 
Table 4

"Off" time and "on" time prior to start of conversion and at end of conversion (conversion completers)

\begin{tabular}{|c|c|c|c|c|c|c|}
\hline \multirow[t]{2}{*}{ Variable } & \multicolumn{3}{|c|}{$\begin{array}{l}\text { Conversion from } \\
\text { IR CD-LD }\end{array}$} & \multicolumn{3}{|c|}{$\begin{array}{l}\text { Conversion from } \\
\text { CLE }\end{array}$} \\
\hline & $\begin{array}{l}\text { Prior to start } \\
\text { of conversion } \\
\text { (IR CD-LD) }\end{array}$ & $\begin{array}{c}\text { End of } \\
\text { conversion } \\
\text { to IPX066 }\end{array}$ & $\begin{array}{l}\text { Change; } \\
p \text {-value }^{\mathrm{a}}\end{array}$ & $\begin{array}{l}\text { Prior to start } \\
\text { of conversion } \\
\text { (CLE) }\end{array}$ & $\begin{array}{c}\text { End of } \\
\text { conversion } \\
\text { to IPX066 }\end{array}$ & $\begin{array}{l}\text { Change; } \\
p \text {-value }\end{array}$ \\
\hline$n$ & 393 & 393 & 393 & 91 & 91 & 91 \\
\hline $\begin{array}{l}\text { "Off” time (hours/day), } \\
\text { mean (SD) }\end{array}$ & $5.6(2.0)$ & $3.9(2.2)$ & $\begin{array}{l}-1.8(2.4) \\
p<0.0001\end{array}$ & $5.9(2.6)$ & $3.8(2.5)$ & $\begin{array}{l}-2.2(2.7) \\
p<0.0001\end{array}$ \\
\hline $\begin{array}{l}\text { "On" time without troublesome } \\
\text { dyskinesia (hours/day) }{ }^{\mathrm{b}} \text {, mean (SD) }\end{array}$ & $10.4(2.3)$ & $12.1(2.7)$ & $\begin{array}{c}1.7(2.6) \\
p<0.0001\end{array}$ & $9.9(2.9)$ & $11.7(2.9)$ & $\begin{array}{c}1.9(2.7) \\
p<0.0001\end{array}$ \\
\hline $\begin{array}{l}\text { "On" time with troublesome } \\
\text { dyskinesia (hours/day), mean (SD) }\end{array}$ & $0.3(1.0)$ & $0.4(1.0)$ & $\begin{array}{c}0.0(0.8) \\
p=0.3845\end{array}$ & $0.6(1.1)$ & $0.6(1.2)$ & $\begin{array}{c}0.0(1.1) \\
p=0.8127\end{array}$ \\
\hline
\end{tabular}

${ }^{a}$ By paired $t$-test. " "On" time without dyskinesia plus "on" time with non-troublesome dyskinesia. CD, carbidopa; CLE, immediate-release carbidopa-levodopa plus entacapone; IR, immediate-release; LD, levodopa; SD, standard deviation.

Table 5

Adverse events during conversion to IPX066 (all treated patients)

\begin{tabular}{lcc}
\hline Variable & $\begin{array}{c}\text { Conversion } \\
\text { from } \\
\text { IR CD-LD }\end{array}$ & $\begin{array}{c}\text { Conversion } \\
\text { from } \\
\text { CLE }\end{array}$ \\
\hline$N$ & 450 & 110 \\
Summary statistics, $n(\%)$ & $206(45.8)$ & $34(30.9)$ \\
Any AE & $160(35.6)$ & $26(23.6)$ \\
Mild & $85(18.9)$ & $14(12.7)$ \\
Moderate & $15(3.3)$ & $2(1.8)$ \\
Severe & $14(3.1)$ & $2(1.8)$ \\
Any serious AE & $23(5.1)$ & $1(0.9)$ \\
Discontinuation due to AEs & $2(0.4)$ & 0 \\
Death & & \\
AEs by Preferred Term ${ }^{\mathrm{a}}, n(\%)$ & $25(5.6)$ & $1(0.9)$ \\
Dyskinesia & $24(5.3)$ & $8(7.3)$ \\
Nausea & $19(4.2)$ & $2(1.8)$ \\
Headache & $17(3.8)$ & $1(0.9)$ \\
Dizziness & $14(3.1)$ & 0 \\
On and off phenomenon & $12(2.7)$ & $3(2.7)$ \\
Fall & $11(2.4)$ & $1(0.9)$ \\
Anxiety & $11(2.4)$ & 0 \\
Dry mouth & $11(2.4)$ & $1(0.9)$ \\
Insomnia & $9(2.0)$ & $1(0.9)$ \\
Constipation & $7(1.6)$ & $3(2.7)$ \\
Vomiting & $5(1.1)$ & $3(2.7)$ \\
Upper respiratory tract infection & & \\
\hline AEs are those reported in $22.0 \%$ & (2) & \\
\hline
\end{tabular}

${ }^{a}$ AEs are those reported in $\geq 2.0 \%$ of patients who began conversion to IPX066 in either study, and are listed by Medical Dictionary for Regulatory Activities Version 12.1 Preferred Term. AE, adverse event; CD, carbidopa; CLE, immediate-release carbidopa-levodopa plus entacapone; IR, immediate-release; LD, levodopa.

or $0.4 \%$ ). During conversion from CLE, one patient $(0.9 \%)$ discontinued due to AEs (dyspepsia, nausea, and vomiting).

\section{DISCUSSION}

In this large sample of patients with advanced PD and $\geq 2.5$ hours/day of daily "off" time despite stable regimens of standard CD-LD formulations, a large majority-overall, $86.4 \%$-were successfully converted from IR CD-LD, either taken alone or with adjunctive entacapone, to a stable IPX066 dosage within a 6-week conversion period. Although their end-of-conversion LD dosages, taken as IPX066, were substantially higher than their previous LD dosages (taken as IR CD-LD or as CLE), mean changes in diary data showed a significant decrease in daily "off" time with no significant increase in troublesome dyskinesia. In addition, during IPX066 treatment, patients took a median of 3 doses/day, compared with 5 doses/day during IR CD-LD or CLE treatment. More than $90 \%$ of patients were taking IPX066 either 3 or 4 times/day (see Table 3).

The observed increases in daily LD dosage and decreases in dosing frequency likely reflect pharmacokinetic differences between IPX066 and the patients' prior LD regimens [18]. In a crossover study of individualized IPX066 treatment versus IR CD-LD in patients with advanced $\mathrm{PD}$, plasma $\mathrm{LD}$ levels remained above $50 \%$ of $\mathrm{C}_{\max }$ for a mean (SD) of 4.0 (2.0) hours for IPX066, compared with 1.4 (0.7) hours for IR CDLD [14]. Furthermore, following repeated dosing, the mean $\mathrm{C}_{\max } / \mathrm{C}_{\min }$ ratio during a 12-hour period was significantly lower for IPX066 than for IR CD-LD, at 12.0 versus 82.2 [14]. The fluctuation index, calculated as $\left(\mathrm{C}_{\max }-\mathrm{C}_{\min }\right) / \mathrm{C}_{\text {average }}$, was also significantly lower, at 1.5 for IPX066 versus 3.2 for IR CD-LD [14]. IPX066 was designed to rapidly attain and sustain therapeutic plateau concentrations of plasma LD, in effect "filling in" the troughs in LD concentration between doses of standard oral LD formulations. In the present studies, the observed IPX066-related LD dose increases may also have helped rectify previous under-treatment. For inclusion, all of the patients had at least 2.5 hours/day of "off" time, and in fact averaged 6 hours/day despite their stable regimens of standard LD 
formulations. In both studies, conversion to IPX066 yielded a significant decrease in daily "off" time, an increase in "on" time without troublesome dyskinesia, and no significant increase in troublesome dyskinesia relative to pre-conversion values. These improvements were maintained during double-blind IPX066 use.

Overall, the results of these studies suggest that the IPX066-initiation tables guiding conversion from IR CD-LD (Table 1, top) or CLE (Table 1, bottom) are appropriate starting points for achieving an effective IPX066 regimen. Patients taking CLE may need to be started on a higher dose of IPX066 than patients taking IR CD-LD, to account for the loss of entacapone, which acts to increase LD exposure [7]. In Table 1, the suggested initial IPX066 doses are approximately $30 \%$ higher for the ASCEND-PD trial compared with the ADVANCE-PD trial, reflecting this expectation. The higher mean conversion ratio among conversion completers who had been using CLE as opposed to those who had been using IR CD-LD-2.8 versus 2.1 - is also consistent with this expectation. Responses during dose conversion are likely to vary from patient to patient, warranting tailored adjustments after the initial conversion to IPX066. Indeed, while more than half of both studies' patients required an increased IPX066 dosage, more than a tenth required a decrease, highlighting the importance of frequent monitoring and individualized adjustments. In all patients, initial follow-up should take place soon after initiation, e.g., within 1 week.

In general, conversion to IPX066 from IR CD-LD or from CLE was well tolerated. The most frequently reported AEs during the 6-week conversion period were AEs associated with dopaminergic therapy. Nausea had a reported incidence of $5.3 \%$ to $7.3 \%$. Despite the higher LD exposure after switching to IPX066, the incidence of dyskinesia as a reported $\mathrm{AE}$ was low, at $0.9 \%$ to $5.6 \%$ across studies. Small numbers of patients $(0.9 \%$ to $5.1 \%$ ) discontinued their conversion because of AEs.

The present report is limited by the requirement in each study that patients maintain stable dosages of adjunctive PD drugs. The studies therefore did not explore the extent to which the use of IPX066 might permit simplification of a patient's overall PD regimen. Additionally, the studies did not investigate long-term post-conversion outcomes; however, a 9month open-label extension study is now completed and has reported encouraging findings [25]. The experience gained in the studies reported here suggests that patients taking standard CD-LD formulations for control of motor symptoms in advanced PD can achieve a stable, tolerable IPX066 regimen with a dosing fre- quency less than that of their prior LD treatment, with associated improvements in motor symptoms $[15,16]$.

\section{ACKNOWLEDGMENTS}

These studies were funded by Impax Laboratories, Inc. Impax participated in the study design, data collection, interpretation and analysis, writing and editing the manuscript, and submission of the manuscript for publication. Medical writing support was provided by Michael Feirtag of The Curry Rockefeller Group, LLC, supported by Impax Laboratories, Inc.

\section{CONFLICTS OF INTEREST}

PAN has received honoraria from Impax Laboratories, Inc., for consulting services and as an investigator. He has spoken on behalf of Novartis, UCB, Inc., and Teva Pharmaceuticals. He has held stock in the following companies Abbott Laboratories, BristolMyers Squibb, Celgene, Dow Chemical, DuPont, Durata Therapeutics, Eli Lilly, Gilead, GlaxoSmithKline, Humana, Impax Laboratories, Inc., Johnson and Johnson, Neogen, Phytopharm plc, Roche Holding, Sigma-Aldrich, and Teva Neuroscience. Lastly, he has received financial support from Adams Pharmaceuticals, Aurora Health Care Foundation, Biotie Therapies, Greater Milwaukee Foundation, Helen Bader Foundation, Icon Clinical Research, Impax Laboratories, Inc., Milwaukee County Department of Family Care, Pharmanet LLC, PRA International, Quintiles Inc., Schwarz Biosciences/UCB, Wisconsin Parkinson Association, and XenoPort.

$\mathrm{AH}$ was an employee of Impax Laboratories, Inc., when the studies were conducted and owns Impax stock.

LE has received honoraria for speaking engagements from Lundbeck, Novartis, UCB Pharma, and Teva Neuroscience; has served as a paid consultant for Teva Neuroscience and UCB Pharma; has received honoraria as a member of advisory boards for Lundbeck, Teva Neuroscience, and UCB Pharma; and has received unrestricted educational grant support from Teva Neuroscience.

RAG has received honoraria from Impax Laboratories, Inc., for consulting services, advisory board services, and as an investigator. He also has received honoraria for speaking engagements from Allergan, Impax, US WorldMeds, Ipsen, and Merz.

JS has indicated that he has nothing to disclose.

CS has received honorarium from US WorldMeds. He also has obtained grants from UCB, Allergan, Teva, and Prana. 
SKhanna, RR, SKell, NBM, and SG are employees of Impax Laboratories, Inc., and own Impax stock and/or stock options.

\section{REFERENCES}

[1] Olanow CW, Stern MB, \& Sethi K (2009) The scientific and clinical basis for the treatment of Parkinson disease. Neurology, 72(21 Suppl 4), S1-S136.

[2] Fox SH, Katzenschlager R, Lim SY, Ravina B, Seppi K, Coelho M, Poewe W, Rascol O, Goetz CG, \& Sampaio C (2011) The Movement Disorder Society Evidence-Based Medicine Review Update: Treatments for the motor symptoms of Parkinson's disease. Mov Disord, 26(Suppl 3), S2-S41.

[3] Cedarbaum JM (1987) Clinical pharmacokinetics of antiparkinsonian drugs. Clin Pharmacokinet, 13, 141-178.

[4] Nutt JG, Woodward WR, \& Anderson JL (1985) The effect of carbidopa on the pharmacokinetics of intravenously administered levodopa: The mechanism of action in the treatment of parkinsonism. Ann Neurol, 18, 537-543.

[5] Chase TN, Baronti F, Fabbrini G, Heuser IJ, Juncos JL, \& Mouradian MM (1989) Rationale for continuous dopaminometic therapy of Parkinson's disease. Neurology, 39, 7-10.

[6] Olanow CW, Obeso JA, \& Stocchi F (2006) Continuous dopamine-receptor treatment of Parkinson's disease: Scientific rationale and clinical implications. Lancet Neurol, 5, 677-687.

[7] Nutt JG, Woodward WR, Beckner RM, Stone CK, Berggren K, Carter JH, Gancher ST, Hammerstad JP, \& Gordin A (1994) Effect of peripheral catechol-O-methyltransferase inhibition on the pharmacokinetics and pharmacodynamics of levodopa in parkinsonian patients. Neurology, 44, 913-919.

[8] Ahlskog JE, Muenter MD, McManis PG, Bell GN, \& Bailey PA (1988) Controlled-release Sinemet (CR-4): A doubleblind crossover study in patients with fluctuating Parkinson's disease. Mayo Clin Proc, 63, 876-886.

[9] Stocchi F, Quinn NP, Barbato L, Patsalos PN, O'Connel MT, Ruggieri S, \& Marsden CD (1994) Comparison between a fast and a slow release preparation of levodopa and a combination of the two: A clinical and pharmacokinetic study. Clin Neuropharmacol, 17, 38-44.

[10] Nyholm D, \& Lennernäs H (2008) Irregular gastrointestinal drug absorption in Parkinson's disease. Expert Opin Drug Metab Toxicol, 4, 193-203.

[11] LeWitt PA, Jennings D, Lyons KE, Pahwa R, Rabinowicz AL, Wang J, Guarnieri M, Hubble JP, \& Murck H (2009) Pharmacokinetic-pharmacodynamic crossover comparison of two levodopa extension strategies. Mov Disord, 24, 1319. 1324.

[12] Cedarbaum JM, Hoey M, \& McDowell FH (1989) A doubleblind crossover comparison of Sinemet CR4 and standard Sinemet 25/100 in patients with Parkinson's disease and fluctuating motor performance. J Neurol Neurosurg Psychiatry, 52, 207-212.

[13] Deleu D, Jacques M, Michotte Y, \& Ebinger G (1989) Controlled-release carbidopa/levodopa (CR) in parkinsonian patients with response fluctuations on standard levodopa treatment: Clinical and pharmacokinetic observations. Neurology, 39(Suppl 2), 88-92.
[14] Hauser RA, Ellenbogen AL, Metman LV, Hsu A, O'Connell MJ, Modi NB, Yao HM, Kell SH, \& Gupta SK (2011) Crossover comparison of IPX066 and a standard levodopa formulation in advanced Parkinson's disease. Mov Disord, 26, 2246-2252.

[15] Hauser RA, Hsu A, Kell S, Espay AJ, Sethi K, Stacy M, Ondo W, O'Connell M, Gupta S, \& IPX066 ADVANCE-PD investigators (2013) Extended-release carbidopa-levodopa (IPX066) compared with immediate-release carbidopalevodopa in patients with Parkinson's disease and motor fluctuations: A phase 3 randomised, double-blind trial. Lancet Neurol, 12, 346-356.

[16] Stocchi F, Hsu A, Khanna S, Ellenbogen A, Mahler A, Liang G, Dillmann U, Rubens R, Kell S, \& Gupta S (2014) Comparison of IPX066 with carbidopa-levodopa plus entacapone in advanced PD patients. Parkinsonism Relat Disord, 20, 13351340 .

[17] Tetrud J, Liang G, Nausieda P, Hsu A, O'Connell M, Khanna S, Kell S, Ellenbogen A, Tanner CM, \& Gupta S (2014) Open-label comparison of IPX066, a novel investigational carbidopa-levodopa (CD-LD) extended-release formulation, and controlled-release CD-LD (CR) in Parkinson's disease patients with motor fluctuation. Poster presented at the 18th International Congress of the International Parkinson and Movement Disorder Society, Stockholm, Sweden, June 8-12, 2014.

[18] Hsu A, Yao HM, Gupta S, \& Modi NB (2015) Comparison of the pharmacokinetics of an oral extendedrelease capsule formulation of carbidopa-levodopa (IPX066), with immediate-release carbidopa-levodopa (Sinemet ${ }^{\circledR}$ ), sustained-release carbidopa-levodopa (Sinemet ${ }^{\circledR} \mathrm{CR}$ ), and carbidopa-levodopa-entacapone (Stalevo ${ }^{\circledR}$ ). J Clin Pharmacol, 55, 995-1003.

[19] Hauser RA (2015) How to dose carbidopa and levodopa extended-release capsules (Rytary). Clin Med J, 1, 34-37.

[20] Hsu A, O’Connell M, Khanna S, Kell S, Rubens R, Ellenbogen A, Nausieda P, Spiegel J, Tanner C, \& Gupta S (2013) IPX066 dose conversion in patients with advanced Parkinson's disease (PD). Poster presented at the 3rd World Parkinson Congress, Montreal, Canada, October 1-4, 2013.

[21] Hsu A, Khanna S, Kell S, Espay A, Gill R, Singer C, \& Gupta S (2013) Dose conversion to IPX066 in advanced Parkinson's disease patients treated wih carbidopa-levodopa-entacapone. Poster presented at the 17 th International Congress of the International Parkinson and Movement Disorder Society, Sydney, Australia, June 16-20, 2013.

[22] Hughes AJ, Daniel SE, Kilford L, \& Lees AJ (1992) Accuracy of clinical diagnosis of idiopathic Parkinson's disease: A clinico-pathological study of 100 cases. J Neurol Neurosurg Psychiatry, 55, 181-184.

[23] Hoehn MM, \& Yahr MD (1967) Parkinsonism: Onset, progression and mortality. Neurology, 17, 427-442.

[24] Hauser RA, Friedlander J, Zesiewicz TA, Adler $\mathrm{CH}$, Seeberger LC, O'Brien CF, Molho ES, \& Factor SA (2000) A home diary to assess functional status in patients with Parkinson's disease with motor fluctuations and dyskinesia. Clin Neuropharmacol, 23, 75-81.

[25] Waters CH, Nausieda P, Dzyak L, Spiegel J, Rudzinska M, Silver DE, Tsurkalenko ES, Kell S, Hsu A, Khanna S, \& Gupta S (2015) Long-term IPX066 in early and advanced PD: A 9-month open-label extension trial. CNS Drugs, 29, 341-350. 